\title{
Appealing to the restless consumer
}

\author{
Judy Illes and Oksana Suchowersky
}

Grappling with limitations of public access to modern medical advances is a tremendous challenge in virtually every country. Many policy makers and consumers have, therefore, welcomed movement away from governmental dictates towards empowerment of individual consumers with both information and control of the health-care dollar. The introduction of direct to consumer (DTC) marketing of pharmaceuticals in the US and New Zealand is one such step, and two new advertisements, focused on restless legs syndrome (RLS), are recent examples.

RLS, which is characterized by an uncontrollable urge to move the legs, particularly in the evening and nocturnal hours, is estimated to affect approximately $10 \%$ of the population (Berger K et al. [2004] Arch Intern Med 164: 196-202). The diagnosis remains subjective as no confirmative diagnostic tests are available, and there is a concern that the condition remains underdiagnosed and, by extension, undertreated. Dopaminergic drugs have been shown in several clinical trials to be an effective therapy for RLS. In an effort to reach consumers directly, the makers of the nonergot dopaminergic medications pramipexole (Mirapex ${ }^{\circledR}$; Boehringer Ingelheim, Ingelheim, Germany) and ropinirole (Requip ${ }^{\circledR}$; GlaxoSmithKline, Uxbridge, UK) recently created television commercials featuring these drugs (available at http://www.mirapex.com/commercial.jsp and www.requip.com/tv_commercial.html).

These advertisements have a few troubling aspects, which also pervade DTC advertising of pharmaceuticals as a whole. A major concern relates to the adverse effects of drugs; these should never be trivialized for any reason, and certainly not for the purposes of increasing or maintaining sales. GlaxoSmithKline declares that the adverse effects of Requip ${ }^{\circledR}$ _ faintness, nausea and dizziness - are not usually very bothersome, and most people do not stop taking the drug. Encouraging patients to defer to the behavior of the population, however, is neither an appropriate nor a responsible health message.
... adverse

effects of drugs ... should never be trivialized for any reason, and certainly not for the purposes of increasing or maintaining sales

J Illes is Canada Research Chair in Neuroethics and Professor of Neurology, University of British Columbia, Vancouver, $B C$, Canada.

O Suchowersky is Professor and Head of the Department of Medical Genetics, and Director of the Movement Disorders Program, University of Calgary, AB, Canada, and an Advisory Board member of Nature Clinical Practice Neurology.

\section{Competing interests}

The authors declared no competing interests.

www.nature.com/clinicalpractice doi:10.1038/ncpneuro0739
The Mirapex ${ }^{\circledR}$ advertisement is almost comedic in its seemingly light treatment of adverse effects. For example, this commercial raises the possibility of increases in gambling and sexual behavior ("intense urge"). These two phenomena are often linked to disinhibitory behavior arising from prefrontal pathology and, whether mild or profound, can be accompanied by substantial lack of insight. In this case, suggesting that a patient who might begin to exhibit these signs should come forward for physician consultation is practically an oxymoron-it is the very patients who suffer from such a disorder who are likely to lack the insight to do so. In addition, the language might even attract some consumers through its specific suggestion that heightened sexual urge is a possibility.

Having noted these shortcomings, it is equally important to explore the potential benefits of consumer-directed health care. First, the sheer visibility that DTC advertising gives health care has the effect of increasing awareness, and provides ever-increasing possibilities for interventions into health problems ranging from the mildly annoying to the devastating. A further benefit is patient empowerment. Individuals taking control of their own health care is highly desirable for them and for society, assuming that appropriate access to information, full disclosure about risks, and assistance for follow-up by physicians are available. Promoting self-diagnosis is not an example of genuine patient empowerment, however ("I had restless legs syndrome-my doctor confirmed it" [Requip ${ }^{\circledR}$ advertisement]), but rather an illusory form of empowerment and a risky business for even the most skilled expert.

The availability of a wide range of health information on the Internet, television and radio can be extremely positive, but by its very nature in the open marketplace this information is limited in quality, completeness, and reliability. Caution and vigilance by individual physicians, coupled with measured enthusiasm by consumers, is needed to ensure that the benefits of the DTC practice outweigh its risks. 